\title{
Orbital Location of Non-Hodgkin's Lymphoma Type B: About A Case
}

\author{
Rabii Laababsi*, Mohamed Amine Allouane, Anass Bouzbouz, Sami Rouadi, Reda Abada, Mohamed \\ Roubal and Mohamed Mahtar
}

Department of ENT, Ibn Rochd University Hospital, Morocco

Received: June 18, 2018; Published: July 03, 2018

*Corresponding author: Rabii Laababsi, Department of ENT, 20 Août hospital, Ibn Rochd University Hospital, Casablanca, Morocco

\section{Abstract}

Non-Hodgkin's lymphoma with orbital location is a relatively rare tumor with a difficult diagnosis. We report the case of a 54-year-old patient with bilateral exophthalmos. Orbital biopsy allowed the diagnosis of diffuse type B lymphoma. The diagnosis is pathological and immunohistochemical. The treatment consisted of a poly-chemotherapy with a multidisciplinary management.

Keywords: Lymphoma; Non Hodgkin; Orbit; Exophthalmos; Chemotherapy

\section{Introduction}

Non-Hodgkin's lymphoma with orbital location is a relatively rare tumor and difficult diagnosis, orbital location accounts for 5 to $10 \%$ of orbital expansive processes [1] The confirmation of the diagnosis is made by histology and immun histochemistry, the treatment consists of poly chemotherapy with multidisciplinary care.
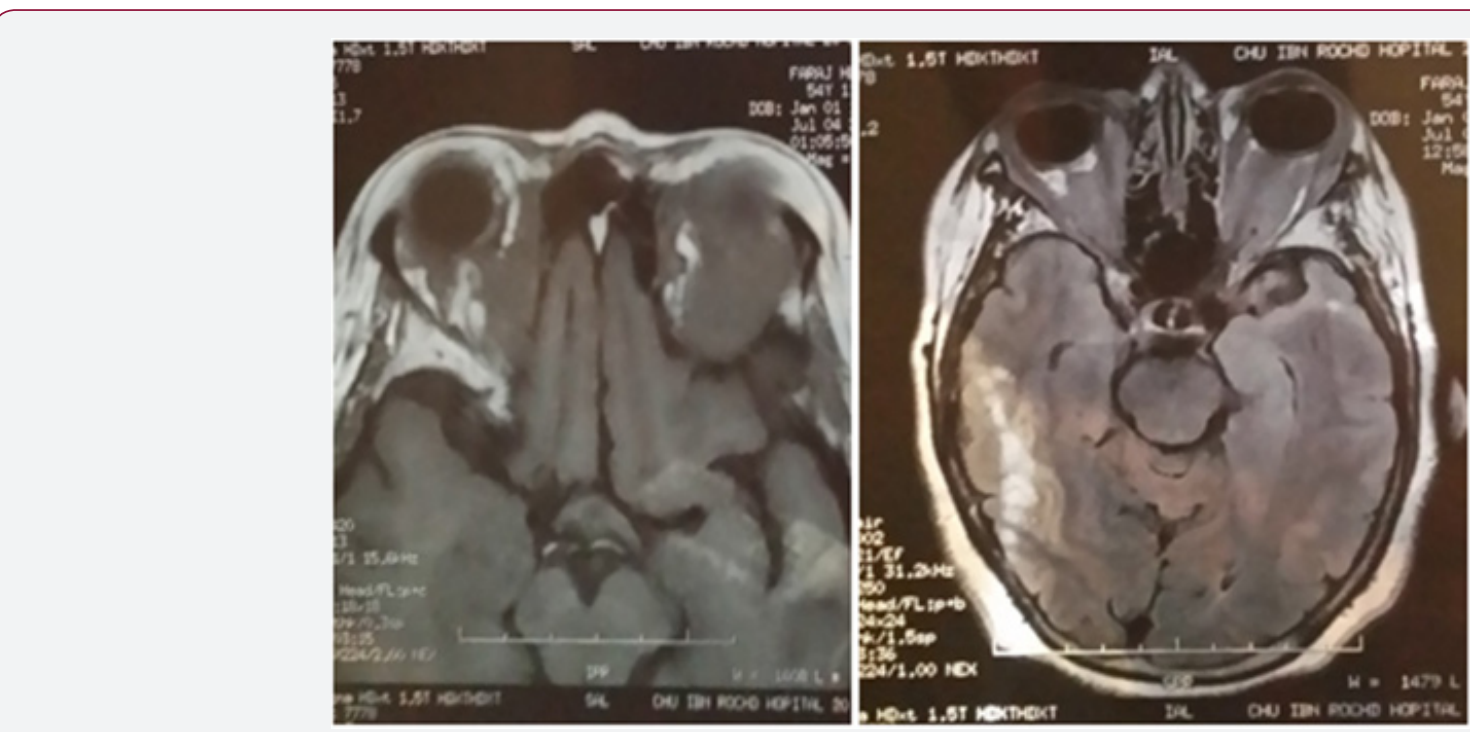

Figure 1: Axial MRI showing the presence of bilateral intra-orbital processes.

\section{Observation}

It is a 54-year-old patient, with no particular pathological history, who presented a left exophthalmia and then progressive right in six months, with preservation of the general condition. The clinical examination found a visual acuity at $7 / 10$ on the right and $5 / 10$ on the left, a photo-motor reflex preserved. The biological assessment showed a blood count, normal renal, hepatic functions and negative HIV serology. 
Magnetic resonance imaging (MRI) revealed the presence of intra-orbital processes, retro septal intra and extra-conical, responsible for an exophthalmitis grade 1 right and grade 2 left (Figure 1). A biopsy was made at the block, under general anesthesia and endoscopically, the histopathological examination of the biopsy showed a diffuse proliferation of lymphomatosis cells of medium size, presenting a mature chromatin nucleus and cleaved contour.
Immunohistochemistry confirmed the diagnosis of diffuse B-cell lymphoma with negativity of ck and chromogranin and CD3 and CD20 (Figure 2). To date, the patient has received three courses of a polychemotherapy type rituximab-CHOP (ciclophosphamideadriablastinevincristine-prednisolone). The follow-up is only five months but the evolution has been towards a stabilization of the attack.

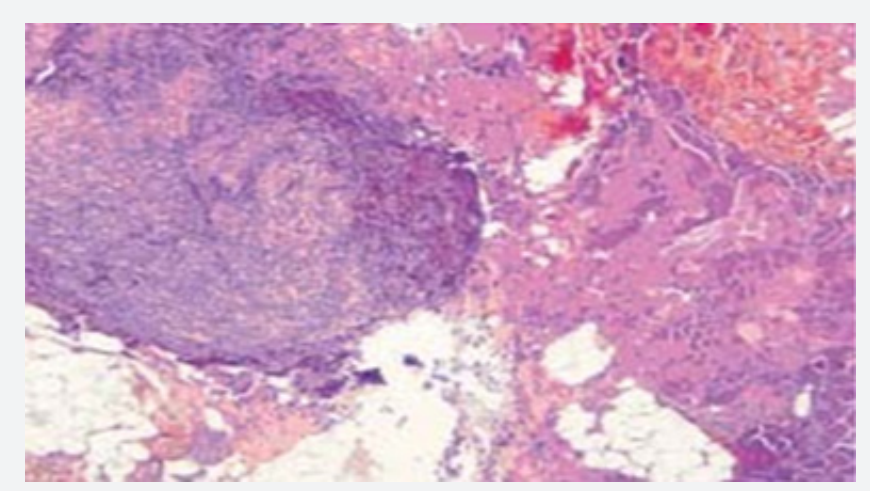

Figure 2: Infiltration of the orbital muscle and adipose tissue by lymphomatous tumor proliferation.

\section{Discussion}

Non-Hodgkin's lymphoma with orbital location accounts for 5 to $10 \%$ of orbital expansive processes [1-3]. According to Ducrey [4], they constitute $4 \%$ of non-traumatic orbital conditions. The orbital localization is rare, objectified at $2 \%$ of all Lymphomas [5]. T-cell and B-cell lymphomas are the most frequent at the orbital level. The incidence of ocular lymphoma in ocular appendages in the United States is estimated at about 43,000 new cases per year, with a higher incidence in white populations than in black populations [67]. The increase in HIV cases alone does not explain the increase in the incidence of non-Hodgkin's lymphoma. Multiple environmental factors appear to be incriminated and are under study.

The average age of onset is 65.8 with a female predominance. The disease is progressive and indolent with an average duration of the symptomatology depending on the site and tumor volume. The most common clinical sign is a periocular mass that can lead to exophthalmia or diplopia. The imaging highlights two evocative aspects, a well-defined mass with fuzzy contours that can mold on the eyeball, optic nerve or bone wall, or an infiltrating form extending into the eyelid, the subcutaneous planes or intra and extra-conical adipose tissue and more or less including muscle and optic nerve [2].

CT shows a density close to that of muscles with moderate enhancement after contrast injection.

The MRI shows:

i. T1 sequence: signal close to that of the muscles.

ii. T2 sequence: moderately hypo or hyper intense, the enhancement is net after injection of PDC.

Bone damage is rare, the extension assessment must be complete and carried out in a specialized department. It conditions the care that must be Multidisciplinary. The diagnostic examination of certainty remains the biopsy, it allows an anatomo pathological examination more or less accompanied by an immunohistochemical study, even genetic. In isolated low-grade lymphomas, the appropriate course of action is clinical and paraclinical surveillance; for symptomatic or high-grade forms, chemotherapy combined with localized radiotherapy will be the gold standard first-line treatment. New therapeutics appear to be effective in lower grade lymphomas to note the anti CD20 antibody. The prognosis depends mainly on the histological form, disease-free survival rates and overall survival at 5 years are $64 \%$ and $79 \%$ for low-grade lymphoma and $43 \%$ and $50 \%$ for high-grade lymphomas. .

\section{Conclusion}

Orbital lymphoma is a rare disorder, often of indolent evolution the diagnosis can only be asserted by the pathological +/- immunohistochemical study. The MRI and if not the orbital CT allow to give a precise assessment of extension which conditions the management, the main differential diagnosis is the pseudoinflammatory tumor.

\section{References}

1. Jakobiec FA, Bilyk JR, Font RL (1996) Orbit. In: Spencer WH (Eds.). Ophthalmic pathology: an atlas and textbook, (4 $4^{\text {th }}$ edn.), Philadelphia, Saunders pp. 2686-2924.

2. L Benabid, B Desablens, M Brevet (2005) Les lymphomes malins non hodgkiniens conjonctivo-orbitaires , J Fr Ophtalmol 28(10): 1058-1064.

3. Wotherspoon AC, Diss TC, Pan LX (1993) Primary low-grade B-cell lymphoma of the conjonctiva: a mucosa-associated lymphoid tissue type lymphoma. Histopathology 23(5): 417-424.

4. Ducrey N (1994) Les lymphomes orbitaires. Ophtalmologie 8: 253-256.

5. Jenkins C, Rose GE, Bunce C, WrightJE, Cree IA, et al. (2000) Histolological features of ocular adnexal lymphoma (REAL classification) and their association with patient morbidity and survival. Br J Ophthalmol 84(8): 907-913. 
6. Ben Haim S, Bar Shalom R, Israel O, Gaitini D, Haim N, et al. (1995) Liver involvement in lymphoma: role of gallium-67 scintigraphy. J Nucl Med 36(5): 900-904.

\section{(c) (i) This work is licensed under Creative}

Submission Link: https://biomedres.us/submit-manuscript.php
7. Carli PM, Maynadie M (2002) Epidémiologie et étiologie des lymphomes non-Hodgkiniens. La Revue du Praticien 52(9): 945-949.

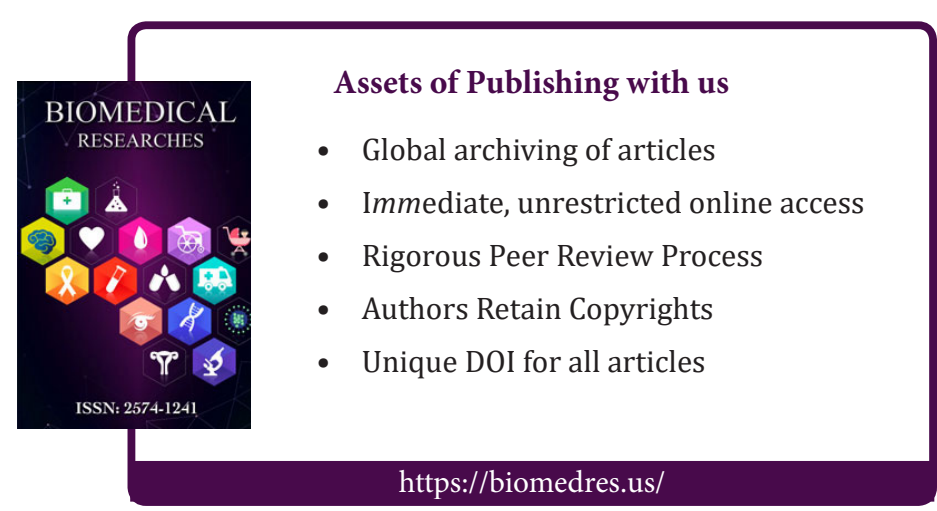

